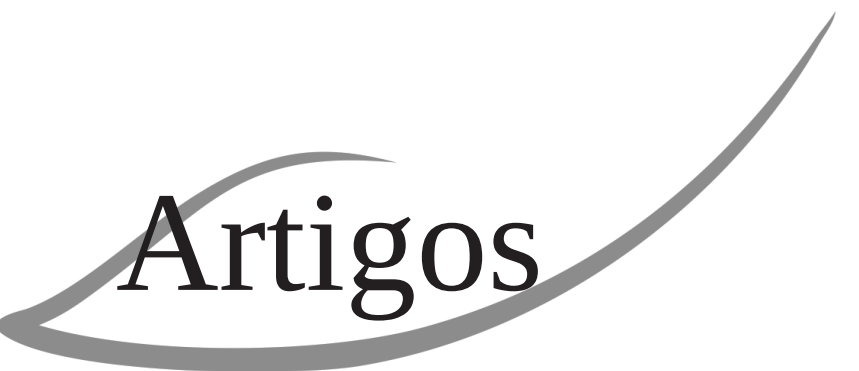




\title{
Extensão universitária no currículo das licenciaturas: inovação e relação de sentido
}

\section{University outreach in the undergraduate curriculum: innovation and sense relation}

\author{
Rosemary Ferreira da Silva* \\ Marise Marçalina de Castro Silva Rosa**
}

\begin{abstract}
Resumo: O presente trabalho apresenta uma discussão sobre a extensão universitária como elemento curricular na formação de professores, ressaltando seu papel na construção de saberes necessários ao exercício da docência, em uma perspectiva inovadora, a partir da concepção de inovação pedagógica desenvolvida por Carlos Nogueira Fino, que alia investigação e práticas pedagógicas. Utilizou-se como embasamento teórico a concepção de campo em Pierre Bourdieu, como forma de analisar o espaço social em que os currículos dos cursos de formação de professores são construídos, as relações entre os agentes construtores e a institucionalização do debate. Na análise da recategorização da extensão universitária como elemento curricular impulsionador da construção e desenvolvimento de relações de saber, buscou-se embasamento em Maurice Tardiff e Bernard Charlot. Essas relações, por sua vez, ao serem compreendidas como produções do universo da prática em sua multidimensionalidade, encaminham-se para a discussão efetivada por Angél Pérez Gomez, que atenta para os riscos de descontextualização a que a individualização das práticas pode incorrer. Conclui-se que o desenvolvimento de práticas extensionistas se estabelece como uma rede relacional em que os agentes articulam as demandas sociais e as proposições advindas dos saberes em construção, estabelecendo relações de sentido que se configuram como uma das estruturas dos mecanismos de produção, transmissão e difusão do capital cultural na formação docente.
\end{abstract}

Palavras-chave: Extensão universitária. Currículo. Licenciaturas. Saberes da docência.

Abstract: This paper presents a discussion about university outreach as an element in the teacher training curriculum, emphasizing its role in building the knowledge necessary to carry out teaching from a fresh perspective, using the innovative educational theory developed by Carlos Nogueira Fino, which combines research and teaching practices. Pierre Bourdieu's concepts were used as a theoretical basis to analyze the social space in which the syllabuses of teacher training are created, the relationships between the respective agents, and the institutionalization of the debate. In the analysis of the re-categorisation of university outreach as a boosting curricular element in the construction and development of knowledge, Maurice Tardiff and Bernard Charlot's ideas were referred to. These relationships, being understood as productions of the practical universe in its multidimensionality, refer to Angél Pérez Gomes’s discussion that draws attention to the risks of decontextualization that individualization of practices can provoke. It is concluded that the development of outreach programs is established as a relational network in which agents articulate social demands and propositions resulting

\footnotetext{
* Doutora em Educação pela Universidade de São Paulo. Professora Adjunta da Universidade Federal do Maranhão. E-mail: <srose@ufma.br>.

** Mestrado em Políticas Públicas pela Universidade Federal do Maranhão. Professora da Universidade Federal do Maranhão. E-mail: <mmarcalina@yahoo.com.br>.
} 
in the construction of knowledge, establishing relations of meaning that constitute one of the structures of generation, transmission and distribution of cultural capital in teacher training.

Keywords: University outreach. Curriculum. Teaching courses. Teaching knowledge.

\section{Introdução}

Estudar a extensão universitária a partir de sua inserção no currículo dos cursos de formação de professores requer uma atenção especial sobre os mecanismos que estruturam a construção das práticas profissionais e se constitui, sobretudo, em investigar algo que foi banalizado, sem que a discussão tenha apontado alternativas para a superação da base da problemática, a dicotomia teoria - prática. Outra perspectiva diz respeito à busca por uma construção de práticas inovadoras que se apresentem como alternativas não só metodológicas, mas, também, como formas de compreender a realidade escolar e, assim, em uma perspectiva colaborativa, desenvolver ações capazes de responder aos desafios apresentados cotidianamente.

A formação de professores para a educação básica nas Instituições de Ensino Superior - IES vem historicamente apresentando currículos centrados apenas na reprodução livresca de conteúdos das áreas humanas e sociais, sem que haja preocupação de desenvolver um olhar sobre as construções cotidianas em que as demandas por decisões são urgentes e carecem da mobilização de saberes que nem sempre foram vistos no processo de formação. Além disso, necessitam também de ações específicas, desenvolvidas em relações também específicas, uma vez que os conteúdos são agrupados em disciplinas que giram em torno das interpretações dos docentes e das formas pelas quais são ministradas.
Esta análise é oriunda da vivência como docentes integrantes do "Projeto Escola Laboratório: uma alternativa para melhoria de qualidade do ensino fundamental”, desenvolvido pelo Departamento de Educação I da Universidade Federal do Maranhão - Brasil, desde 1995 até a atualidade. A conexão entre nossas experiências é permeada pela inquietude diante da realidade, pela necessidade de construir e reconstruir conhecimentos, pois a não conformidade com as respostas existentes é constante, já que estas não se mostram capazes de resolver os problemas que o real apresenta.

Observa-se que a participação em ações extensionistas no processo de construção dos saberes da docência vem contribuindo, sobremaneira, para o desenvolvimento do que se pode designar "olhar apurado para o social", olhar que se despe de preconceitos e busca assumir uma cumplicidade com seu público-alvo, por considerar a parceria como algo inevitável. Ao desenvolver esse olhar, a vivência curricular, automaticamente, sofre uma ruptura, uma vez que a busca por conhecimentos é acelerada e imediatamente conectada com a concretude do mundo real, demandando uma análise permanente, o que cria uma insatisfação quase natural com os discursos livrescos que, na maioria das vezes, permeiam a formação de professores.

Em outra perspectiva, constata-se a construção permanente de práticas inovadoras que procurem envolver os alunos na discussão da realidade educacional e suas problemáticas, como que buscando aliados para 
combatê-las, que transmitam conhecimentos contextualizados criando uma relação crítica com o conhecimento. O desenvolvimento dessa relação cria uma inquietude, uma necessidade de construir respostas mesmo que essas perguntas brotem incessantemente. Enfim, a criação de uma prática se faz necessária para uma relação de sentido entre o conhecimento acadêmico, a realidade e sua dinâmica.

$\mathrm{O}$ que se quer propor neste trabalho é uma discussão sobre a inserção da extensão no currículo dos cursos de formação de professores como elemento mobilizador das relações de sentido necessárias à construção dos saberes da docência. Naturalmente, essa inserção será feita a partir da discussão da extensão universitária como elemento curricular propulsor da construção de práticas pedagógicas inovadoras, e não na perspectiva de inserção de novidades de fora para dentro. Como aponta FINO (2010):

A ideia é aliar a investigação, sem a qual os processos pedagógicos não serão completamente inteligíveis, ao intuito de inovar, a partir de um juízo macro sobre a escola na sua generalidade, fundado na investigação. Por outras palavras, trata-se de encarar o investigador como agente transformador, aventurando-se nas areias movediças de não se saber, com nitidez, onde começa um e acaba o outro, ou, caso coexistam, como chegarão ao final sem se desfazer essa harmonia cúmplice entre a dúvida que impele à pesquisa e a certeza que conduz à acção. Trata-se de rejeitar a dicotomia entre a compreensão e seu uso na transformação deliberada, centrada na mania como praticam pessoas que querem aprender, assessoradas por pessoas que têm a responsabilidade de criar contextos de aprendizagem (cada vez mais) ricos e favoráveis. (FINO, 2010, p. 2)
Para desenvolver a discussão iniciase o estudo refletindo o papel da extensão na concepção de processo formador que se constitui como um componente que influencia a concepção de currículo, aqui abordado como um processo que vai sendo construído no decorrer da formação, e não só em sua face explícita, mas principalmente nas construções cotidianas que ocorrem na esfera da concretização do processo de ensino e de aprendizagem.

A seguir discute-se a influência do espaço social - o campo acadêmico - em que ocorre o citado processo, tendo como referência a concepção de Pierre Bourdieu, que afirma ser no exercício de sua autonomia, embora relativa, que são geradas necessidades próprias que influenciam a configuração dos currículos. Nessa perspectiva será analisada a posição da extensão no campo de poder e quanto de capital simbólico ela atribui ao currículo dos cursos de formação de professores.

Ao analisar os agentes envolvidos nas ações extensionistas, busca-se discutir a posição social que eles ocupam no campo acadêmico, a partir do capital simbólico adquirido no desenvolvimento das ações, e quanto de poder é conferido aos extensionistas no processo de legitimação do discurso científico no espaço social acadêmico.

Assim, propõe-se discutir a reconfiguração dos currículos dos cursos de formação de professores a partir da inserção da extensão como ação propulsora da compreensão da dinâmica das relações sociais, base para a construção de práticas inovadoras voltadas para a busca de alternativas e para as demandas geradas no campo educacional. Desse modo, pretendese analisar a multidimensionalidade em que as práticas se configuram, a partir da discussão proposta por Angél Pérez Gomez 
sobre os riscos de descontextualização a que a individualização das práticas incorre, quando seu desenvolvimento restringe-se a processos de transmissão de conhecimentos.

\section{O espaço social da extensão no campo acadêmico}

O campo acadêmico, enquanto campo de poder, é constituído por lutas e oposições que, em sua face explícita, se apresentam como uma comunidade geradora de interesses e objetivos comuns, o que contribui para assegurar o controle sobre a profissão no espaço exterior a esse campo. No entanto,

as lutas estabelecidas nesse universo buscam o poder de impor ao campo ou subcampo um novo conjunto de determinações sobre os quais terão domínio os agentes que dispuserem de maior volume de capital simbólico, de outro lado há os que já dominam o objeto de disputa e lutam para que sejam mantidas as condições vigentes. (SILVA, 2008. p.45)

A complexidade das relações estabelecidas no campo acadêmico se expressa na estrutura e desenvolvimento das formações que lá se desenvolvem, a partir dos códigos legitimados no campo ou subcampo onde estão estabelecidas. Ao se desenvolverem no subcampo acadêmico, as políticas, enquanto integrantes do universo do simbólico, configuram-se com base nas práticas cotidianas nas quais as tensões estão incorporadas como parte do jogo de poder que compatibiliza as ações que estruturam tais relações. Para Rosa (2010, p. 95):

As ações formadoras estabelecem uma dinâmica ao discurso acadêmico que nem sempre desenvolve uma relação de coerência com a estrutura de formação, criando uma representação dicotômica das citadas ações, o que estimula os agentes a mobilizar os esquemas de oposições na luta pela distinção, que de acordo com as relações de poder hegemônicas constituem uma hierarquização, estabelecendo níveis de força a cada uma das referidas ações.

Vista dessa forma - como estrutura de formação e como espaço onde os formadores de professores desenvolvem a prática de ensino como uma prática social viva - a Universidade situa-se como "lócus" de produção de determinadas concepções, crenças, valores e suas culturas engendradas nesse campo. Nessa perspectiva, a extensão pode ser vista como lugar de fronteira e de enfrentamento das lutas em torno das relações e práticas entre os sujeitos formadores e os futuros professores no processo de produção e apropriação de saberes docentes.

Logo, o espaço social onde são construídos e desenvolvidos os currículos de cursos de formação de professores se configura como um espaço de poder, pois nele são tomadas decisões que influenciam nas estruturas de produção, reprodução e difusão do conhecimento. Tais decisões estas relacionadas também às práticas científicas, técnicas e pedagógicas que possibilitam um processo de formação, já que uma estrutura curricular é intencional e se embasa em objetivos explícitos, enquanto as oposições entre os agentes que se relacionam no citado espaço influenciam em sua concretização, configurando objetivos estruturados implicitamente.

Em uma perspectiva, os objetivos explícitos são aqueles integrantes da organização do processo, que descrevem os discursos teóricos, atendem às normas e dão a conhecer à sociedade as intenções das instituições de ensino, no que se refere ao projeto de formação que se predispõem a desenvolver. Em 
outra perspectiva, os objetivos implícitos resultam das disputas existentes no campo, são os que permeiam o cotidiano do fazer pedagógico e que os agentes, na maioria das vezes, tratam de mascarar por meio de um discurso teórico e aparentemente desinteressado, utilizando nesse procedimento os mecanismos de legitimação que são aceitos no campo, para aparentar um comprometimento com as demandas sociais. Tudo isso acontece numa espécie de jogo em que "[...] o jogo com a regra faz parte da regra do jogo" (BORDIEU, 2002, p. 199-200).

A utilização do discurso do comprometimento como mecanismo de legitimação das regularidades que estruturam o jogo em um campo determinado configura-se como um dos elementos utilizados para a compatibilização de comportamentos dos agentes, como forma de garantir a reprodução do sistema de posições existente. Em último caso, ele se constitui em um elemento fundamental para o desenvolvimento do fazer pedagógico, que efetivamente concretiza o currículo.

O subcampo acadêmico e mais especificamente as licenciaturas, instâncias de formação de professores, têm, dentre suas características, as disputas pela definição das áreas de conhecimento a serem contempladas no currículo dos cursos. Portanto, tornam-se, muitas vezes, o único aspecto da formação a merecer atenção nas construções curriculares, principalmente por ter o discurso da prescrição da melhor formação.

Nessa perspectiva, o espaço ocupado pela extensão se configura a partir das relações entre os agentes, as quais são mediadas pelas regras que tecem as condições em que o currículo se efetiva, já que

[...] é a estrutura das relações objetivas entre os diferentes agentes que determina o que eles podem e não podem fazer. Ou, mais precisamente, é a posição que eles ocupam nessa estrutura que determina ou orienta, pelo menos negativamente, suas tomadas de posição. (BOURDIEU, 2004, p. 23)

A extensão, ao ser vista como uma das ações formadoras indissociáveis que compõem o tripé da universidade, a princípio se encontra em posição social equivalente às demais. No entanto, por ser permeada pelo processo de hierarquização oriundo das dicotomias históricas, acaba sendo relegada a uma posição de inferioridade no campo. Essa situação é explicitada pela desvalorização e o pouco investimento atribuído à extensão universitária, pois enquanto os pesquisadores se ocupam das publicações como forma de atrair financiamentos, os extensionistas veem a extensão como uma atividade que conceitualmente se destinava a inserir o formando na realidade social, ao mesmo tempo em que abria um viés de acessibilidade do conhecimento científico à sociedade. Hoje, porém, a extensão transformou-se em um mercado de serviços, principalmente como fonte de captação de recursos, deixando em segundo plano sua perspectiva de formação.

Entretanto, ao ser concebida como elemento curricular, a extensão assume o papel de conectora entre o ensino e a pesquisa, não como mensageira da academia para a sociedade, mas como uma ação mobilizadora dos mecanismos de construção dos saberes da docência, os quais se estruturam a partir da relação de sentido estabelecida no espaço social em que a ação pedagógica se desenvolverá, o que muda a perspectiva que lhe é atribuída pela hierarquização construída pela dinâmica do campo acadêmico.

É a partir da construção da relação de sentido buscada pelos professores em formação que são criadas as experiências inovadoras, uma vez que ao mobilizar conhecimentos para atender à demanda da escola, 
ocorre uma relação de caráter investigativo, propulsora de transformações tanto nas práticas quanto no espaço escolar como um todo. Assim, concebe-se que o desenvolvimento da extensão como elemento curricular na formação de professores contribui não só para a inovação na perspectiva metodológica, mas também para um desenvolvimento curricular inovador.

Em todo esse processo, não se pode deixar de discutir o papel do extensionista, aquele que se rebela contra a rigidez dos papéis estabelecidos no campo acadêmico e busca romper com o que Gómez (2000) chama de descontextualização das práticas, a qual é promovida por uma individualização decorrente do aplicacionismo, em que se atribui a cada sujeito a função de utilizar sua própria síntese no desenvolvimento da ação pedagógica.

É importante destacar que formar-se professor é um processo complexo que implica uma subjetivação de condições objetivas. Ou seja, o formando (aluno) recebe sob forma de currículo um conjunto mecânico de regras e conteúdos para que desenvolva destreza e conhecimento do exercício da docência, o que, por si só, implica compreender as condições de produção e distribuição da cultura para, a partir de sua posição no campo, operar internamente uma forma de expressão que é pessoal, mas se vê legitimada pelo estatuto do campo educacional.

Pode-se inferir, portanto, que a inserção da extensão no currículo dos cursos de formação de professores deverá criar mecanismos que propiciem aos agentes inseridos no campo uma reflexividade. Reflexividade não no sentido de ver de fora, eximindo-se da crítica, mas a reflexividade apresentada na proposta de Bourdieu, em que a análise inclui as práticas não só no nível da execução, mas principalmente no envolvimento das condições em que são produzidas, em que são questionadas coletivamente as bases nas quais as proposições e concretizações se efetivam. Segundo Rosa (2010, p. 22),

A prática extensionista exige uma participação e um processo crítico-reflexivo de todos os atores sociais. Deve contemplar análises de questões que perpassem o processo vivido na Universidade, na sociedade, visando à construção de uma práxis político-pedagógica e educativa, voltada para a construção social de conhecimentos e saberes necessários à formação acadêmica, principalmente na área da docência.

Para a consecução dessa reflexividade, as práticas cotidianas desenvolvidas nas esferas da produção, transmissão e difusão do conhecimento necessitam de conexão e interação, possibilitadas pela extensão universitária, que reconfigura os espaços acadêmicos. Dentre esses espaços, a sala de aula se constituirá num ambiente em que os conteúdos vão contribuir para que a realidade seja questionada, problematizada. Assim, os grupos de estudo devem configurar-se como um espaço de busca de bases para que a compreensão dessa realidade vá além da sua face visível, e o espaço de desenvolvimento das práticas do futuro professor, os ambientes educacionais, se constituam como vias de ligação entre as estruturas de pensamento e as estruturas das práticas.

\section{A extensão universitária e a reconfiguração dos currículos de formação de professores}

Mesmo com os avanços dos estudos, a formação de professores no âmbito das universidades ainda apresenta as dicotomias históricas: forma - conteúdo pedagógico - 
conteúdo sociopolítico e o que fundamenta este trabalho, a teoria-prática responsável por currículos compostos por disciplinas que são ministradas de forma isolada, com os conhecimentos e atividades girando em torno de si, sem vislumbrar sua condição de complementaridade, de articulação. Tais disciplinas são organizadas numa perspectiva de finitude, ou seja, de que tudo se inicia e termina em si mesmo, como se não constituíssem um currículo.

Nos currículos dos cursos de formação de professores, a dicotomia teoria-prática é explicitada por meio da disciplinarização das práticas, nos estágios supervisionados, os quais, na maioria das vezes, são realizados ao final do curso, com o objetivo de promover uma síntese que, por sua vez, deveria embasar o desenvolvimento de uma prática. Os conhecimentos ditos teóricos foram ao longo de toda a formação oriundos dos livros e das interpretações dos formadores, sem qualquer relação com a escola real, que se apresenta como um apêndice curricular.

Outro elemento que demonstra essa dicotomia é a distribuição de carga horária como pode ser observado na Resolução $\mathrm{CNE} / \mathrm{CP} \mathrm{n}^{\circ}$ 2, de 19 de fevereiro de 2002, que institui a duração e a carga horária dos cursos de licenciatura de graduação plena, de formação de professores para a educação básica em nível superior, atendendo ao disposto no artigo 12 da Resolução CNE/CP n ${ }^{\circ}$ 1, de 18 de fevereiro de 2002, que institui as Diretrizes Curriculares Nacionais para a Formação de Professores da Educação Básica, em nível superior, onde está definido que a questão deve ser tratada em parecer e resolução específicos, enquanto os três parágrafos que integram o mesmo artigo são dedicados à inserção da dimensão prática no período em que ocorrerá a formação.
Assim, a Resolução nº 2/2002 institui que a duração e a carga horária dos cursos de licenciatura de graduação plena, de formação de professores para a educação básica em nível superior deverão ocorrer em um mínimo de duas mil e oitocentas horas, a serem desenvolvidas em um tempo mínimo de três anos, assim distribuídos:

I - 400 (quatrocentas) horas de prática como componente curricular, vivenciadas ao longo do curso (BRASIL, 2002). A prática tratada na resolução é distinguida do estágio quando não tem a obrigatoriedade de ser desenvolvida na escola e nem se atém a uma prática pedagógica propriamente dita, embora não prescinda da observação e ação direta, sendo indicada a necessidade de permear todas as disciplinas desde o início do curso, incluindo atividades laboratoriais, de investigação e simulações, utilizando recursos tecnológicos.

II - 400 (quatrocentas) horas de estágio curricular supervisionado a partir da segunda metade do curso (BRASIL, 2002). No parágrafo $3^{\circ}$ do artigo 13 é colocado que esse estágio é definido por lei e deve ser desenvolvido obrigatoriamente em escolas de educação básica, com o objetivo de propiciar o exercício da atividade profissional de forma supervisionada.

III - 1800 (mil e oitocentas) horas de aula para os conteúdos curriculares de natureza científico-cultural (BRASIL, 2002). Aqui estão inseridos os conteúdos específicos e os de natureza didático-pedagógica, cabendo ressaltar que no parágrafo único do artigo 11 da Resolução CNE/CP n ${ }^{\circ}$ 1/2002 está determinado que "[...] o tempo dedicado às dimensões pedagógicas não será inferior à quinta parte da carga horária total dos recursos”. (BRASIL, 2002) 
IV - 200 (duzentas) horas para outras formas de atividades acadêmicas, científicas e culturais (BRASIL, 2002). Aqui estão incluídas as denominadas atividades complementares ou os denominados estudos independentes, ou seja, atividades de livre escolha dos alunos que venham a contribuir no seu processo de formação. (SILVA, 2008, p. 94-95)

\begin{tabular}{l|l|l|}
$\begin{array}{l}\text { Diretrizes Curriculares Nacionais para a } \\
\text { Formação de Professores } \\
\text { Distribuição da carga horária }\end{array}$ \\
\hline Atividades & $\begin{array}{l}\text { Carga Horária } \\
\text { (horas) }\end{array}$ & $\begin{array}{l}\text { Percentual } \\
\text { (\%) }\end{array}$ \\
\hline Atividades Práticas & 400 & 14,3 \\
\hline Estágio Curricular & 400 & 14,3 \\
\hline Conteúdos Didát./Metod. & 560 & 20,0 \\
\hline Conteúdos Específicos & 1240 & 44,3 \\
\hline Atividades Independentes & 200 & 7,1 \\
\hline Total & 2800 & 100 \\
\hline
\end{tabular}

Fonte: Silva, 2008, p. 95.

A lógica da dicotomia teoria/prática é revelada quando se observa no quadro acima que a distribuição da carga horária sugerida para os currículos das licenciaturas destina para as práticas e o estágio 800 horas, enquanto que, se somados os quantitativos de tempo destinados aos conteúdos específicos e aos conteúdos didático-pedagógicos, tem-se 1800 horas. Isso demonstra que os estudos teóricos dispõem de mais do dobro do tempo destinado às atividades práticas, o que reafirma uma relação historicamente construída com base na hierarquia entre o trabalho manual e o trabalho intelectual, a qual, por sua vez, reduz as condições de desenvolvimento de uma formação que tenha como base a investigação e se aproxime do modelo aplicacionista.

Os currículos construídos nessa perspectiva contribuem para uma formação distanciada do lócus onde será realizada a ação pedagógica. Diante disso, tentar-se-á aplicar os conhecimentos acadêmicos na solução dos problemas advindos dessa realidade. E, no caso de fracasso dessa tentativa, a opção imediata talvez seja a do lugar comum: "a teoria na prática é outra”. Embora os resultados das pesquisas apontem o problema, são efetivadas somente tentativas isoladas e de caráter experimental para enfrentar a questão.

O estágio supervisionado nos anos iniciais do ensino fundamental é uma dessas tentativas desde o ano 2000 no curso de Pedagogia da Universidade Federal do Maranhão, a partir da implementação das ações de extensão, o que vem reconfigurando a concretização do currículo. Essa experiência vem se desenvolvendo por meio do Projeto de Extensão Escola-Laboratório: uma alternativa para a melhoria do ensino fundamental, que possibilita aos professores em formação o desenvolvimento do estágio supervisionado por meio de ações pedagógicas complementares, envolvendo crianças residentes no entorno da UFMA, alunas de escolas públicas e comunitárias, com histórico de reprovações nos anos iniciais do ensino fundamental.

As atividades são desenvolvidas a partir de uma investigação que versa sobre: diagnóstico sobre os conhecimentos prévios, hipóteses sobre a língua escrita, condições socioeconômicas, história de vida e demais informações que permitam o conhecimento de cada criança em seu processo de apropriação da língua, como forma de embasar a tomada de decisão sobre os procedimentos didáticos a serem desenvolvidos.

Assim sendo, entendemos o estágio em docência como um campo em que os estagiários vivenciam a tensão do jogo de forças entre os saberes incorporados e a mobilização de saberes necessários na gestão da sala de aula e nos processos de ensino e 
de aprendizagem, considerando a complexidade da escola como lócus de construção da identidade docente, como forma de contribuir para uma ruptura com a mera reprodução dos esquemas de ação observados nos professores em exercício e de construir atividades criadoras no decorrer do estágio.

Para analisar as práticas cotidianas dos estagiários envolvidos no projeto, recorremos ao conceito de habitus em Bourdieu, definido como:

Um conjunto de esquemas que permite engendrar uma infinidade de práticas adaptadas às situações sempre renovadas sem nunca se constituir em princípios explícitos; ou ainda esse sistema de disposições duradouras e transponíveis que, integrando todas as experiências passadas, funciona, em cada momento, como uma matriz de percepções, de apreciações e de ações e torna possível a concretização de tarefas infinitamente diferenciadas, graças às transferências analógicas de esquemas que permitem resolver os problemas da mesma natureza. (BORDIEU, 1992, p. 128-129)

O estágio supervisionado, nessa perspectiva, engendra o habitus professoral enquanto modus operandi, à medida que futuros professores, em suas práticas, incorporam estruturas estruturantes de esquemas de ação estruturados, podendo configurar um novo habitus. As experiências que esses agentes constroem em sala de aula, o modus vivendi manifestado em gestos, vozes e estilos, dentre outros, são incorporados e corporificados em suas práticas como docentes no exercício da profissão.

Tais experiências são importantes porque diversificam as ações do estágio e deslocam o lugar deste como sendo o de mera reprodução, numa perspectiva aplicacionista, para uma prática inovadora nesse campo, situando a extensão universitária como dispositivo curricular e como práxis mediadora na produção/apropriação de saberes diferenciados.

A partir dessa perspectiva, o estágio deixa de se desenvolver no que Tardif (2003) denomina de modelo aplicacionista do conhecimento.

No modelo aplicacionista, o conhecer e o fazer são dissociados e tratados separadamente em unidades de formação distintas e separadas. Além disso, o fazer está subordinado temporal e logicamente ao conhecer, pois ensina-se aos alunos dos cursos de formação de professores que, para fazer bem feito, eles devem conhecer bem e em seguida aplicar seu conhecimento ao fazer. (TARDIF, 2003, p. 271-272)

A dissociabilidade apresentada nesse modelo cria a perspectiva de formação de diferentes perfis profissionais em um mesmo curso. Essas diferenças são pautadas na distribuição desigual de capital cultural investido nos formandos, independentemente do volume de capital cultural herdado que eles possam apresentar no momento do ingresso no curso, pois o aplicacionismo consiste no fato de que

os alunos passam um certo número de anos a assistir a aulas baseadas em disciplinas e constituídas de conhecimentos proposicionais. Em seguida, ou durante essas aulas, eles vão estagiar para “aplicarem” esses conhecimentos. Enfim, quando a formação termina, eles começam a trabalhar sozinhos, aprendendo seu ofício na prática e constatando, na maioria das vezes, que esses conhecimentos proposicionais não se aplicam bem na ação cotidiana. (WIDEEN et al. 1998 apud TARDIF, 2003, p. 270)

A inserção da extensão no currículo de um curso de formação de professores contribui na superação desse modelo quando alia 
a investigação documental a partir do conhecimento da legislação que embasa o desenvolvimento do estágio e do ensino, além dos Parâmetros Curriculares Nacionais para o Ensino Fundamental e do projeto político-pedagógico da escola. E, também, quando de igual modo demanda o estudo conceitual sobre processos metodológicos e um levantamento de dados sobre as relações sociais existentes no campo educacional.

A partir dos dados coletados nessa etapa, aliados aos da investigação de natureza pedagógica e socioeconômica, é elaborado o projeto de intervenção. Além das aulas ministradas para as crianças, esse projeto envolve palestras para os pais e formação contínua para os professores, aliando assim ensino, pesquisa e extensão, o que, por sua vez, altera a configuração do currículo concretizado, tornando-o mais aberto aos conhecimentos construídos, à incorporação de demandas da realidade escolar. Torna também mais flexível esse currículo, já que possibilita um processo de construção do saber que, segundo CHARLOT (2000), envolve a mobilização do sujeito em direção ao conhecimento, constituindo assim uma rede relacional que configura o currículo, ao mesmo tempo em que é por ele reconfigurada.

\section{Referências}

BOURDIEU, Pierre. O poder simbólico. 5. ed. Rio de Janeiro: Bertrand Brasil, 2002.

. Os usos sociais da ciência: por uma sociologia clínica do campo científico. São Paulo: Editora UNESP, 2004.

Vozes, 2009.

O senso prático. Rio de Janeiro:

BRASIL. MEC. Conselho Nacional de Educação. Resolução CNE/CP $n^{0}$ 1, de
18 de fevereiro de 2002. Disponível em: $<$ www.mec.gov.br $>$. Acesso em 20 fevereiro 2007.

Resolução CNE/CP n' 2 de 19 de fevereiro de 2002. Disponível em: <www. mec.gov.br>. Acesso em: 20 fevereiro 2007.

CHARLOT, Bernard. Da relação com o saber: elementos para uma teoria. Porto Alegre: ARTMED, 2000.

FINO, Carlos Nogueira. Investigação e inovação. V colóquio CIE - UMA. Ilha da Madeira - Portugal. Disponível em: <http:// www3.uma.pt/carlosfino/publicacoes/ Investigacao_e_inovacao.pdf $>$. Acesso em: 04 agosto 2011.

GÓMEZ, Angél Perez; SACRISTÁN, J. Gimeno. 4. ed. Compreender e transformar o ensino. Porto Alegre, 2000.

ROSA, Marise M. de C. S.Tecendo uma manhã: o estágio supervisionado no curso de pedagogia mediado pela extensão universitária. São Paulo. 2010. Tese (Doutorado em Educação). Faculdade Filosofia e Ciências - Universidade Estadual Paulista Júlio de Mesquita Filho.

SILVA, Rosemary Ferreira. As políticas curriculares no curso de filosofia da Universidade Federal do Maranhão: relações de poder e a regulação. São Paulo. 2008. Tese (Doutorado em Educação). Faculdade de Educação - Universidade de São Paulo.

TARDIF, Maurice. 3. ed. Saberes docentes e formação profissional. Rio de Janeiro: Vozes, 2003.

Enviado em: 02/08/2011

Aceito em: 20/10/2011 